\title{
PELATIHAN PERANCANGAN MEDIA PROMOSI KESEHATAN KEPADA ANGKATAN MUDA MUHAMMADIYAH KOTA YOGYAKARTA
}

\author{
Oleh: \\ Ahmad Ahid Mudayana, Marsiana Wibowo, Erni Gustina \\ Universitas Ahmad Dahlan Yogyakarta
}

\section{Ringkasan}

Perkembangan informasi sangat pesat di era digital sekarang ini. Pemanfaatan New Media, yaitu digital media yang berbasis internet sebagai sumber informasi sangat tinggi. Keakuratan dan kelayanan publikasi informasi terkadang dipertanyakan khalayak. Intensitas tertinggi pengakses media ini adalah remaja. Remaja merupakan masa yang dilalui individu dan pada periode tersebut keinginan untuk eksplorasi wawasan sangat tinggi. Informasi kesehatan akan sangat mudah didapatkan melalui digital media. Remaja bisa tidak hanya berperan sebagai komunikan dari digital media, namun juga bisa sebagai komunikator informasi kesehatan bagi sesamanya. Tanpa meninggalkan Old Media, New Media merupakan media yang dipilih sekarang ini. Perancangan old media seperti artikel, poster, leaflet bisa dimasukkan ke New Media yang mereka pilih, seperti melalui Blog.

Kata Kunci: Media Promosi, Kesehatan

\begin{abstract}
The development of information is very rapid in the digital era today. Utilization of New Media, the internet-based digital media as a source of information is very high. The accuracy and service of information publication is sometimes questionable to the public. The highest intensity of this media accessor is adolescent. Adolescence is a time passed by individuals and in that period the desire for exploration is very high. Health information will be very easy to get through digital media. Teenagers can not only act as a communicant of digital media, but also as a communicator of health information for each other. Without leaving Old Media, New Media is the currently selected medium. Old media design such as articles, posters, leaflets can be entered into New Media that they choose, such as through Blog.
\end{abstract}

Keywords: Media Promotion, Health

\section{A. PENDAHULUAN}

Perkembangan informasi sangat pesat di era digital sekarang ini. Pemanfaatan New Media, yaitu digital media sebagai media informasi sangat tinggi. Keakuratan dan kelayakan publikasi informasi terkadang dipertanyakan khalayak. Informasi kesehatan akan sangat mudah didapatkan melalui digital media. Tanpa meninggalkan Old Media, New Media merupakan media yang dipilih sekarang ini. Perancangan old media seperti artikel, poster, leaflet bias dimasukkan ke New Media yang mereka pilih, seperti melalui Blog (Parvanta et al. 2011).

Intensitas tertinggi pengakses media ini adalah remaja. Remaja adalah periode individu penuh rasa keingintahuan dalam segala hal. Permasalahan kesehatan yang dilalui individu remaja juga semakin kompleks menuju kondisi negentropy, yaitu kondisi individu sudah bisa dikatakan dewasa, bisa mengambil keputusan untuk kehidupan sendiri, serta 
bisa mengaitkan antara pengetahuan satu dengan yang lain dengan penuh kesadaran dalam aktulisasi di kehidupan sehari-hari. Keaktifan remaja dalam mengeksplorasi pengetahuan dan keterampilan ini sudah seharusnya menjadi peluang besar dalam memperdalam keterampilan remaja, terutama di era informasi dan media yang canggih sekarang ini. Remaja bisa tidak hanya berperan sebagai komunikan dari digital media, namun juga bisa sebagai komunikator informasi kesehatan bagi sesamanya (Sarwono, 2012).

Remaja mempunyai daya tanggap yang cepat dalam mempelajari media, terutama media sosial dan digital. Media merupakan saluran informasi yang digunakan untuk menyampaikan informasi (Simon-Morton, 1995). Media membantu proses pembelajaran, oleh karena itu media harus dipresentasikan dengan baik, mudah dimengerti, akurat. Isi pesan adalah yang dibutuhkan oleh kelompok sasaran. Selain itu, media dapat meningkatkan kepedulian dan ketertarikan individu atau kelompok pada topik kesehata tertentu (Kemm \& Close, 1995). Oleh karena itu, diperlukan keterampilan yang baik bagi remaja agar bisa memanfaatkan media sosialnya untuk kepentingan yang positif dan berguna bagi sesama salah satunya dengan melalui pelatihan perancangan media promosi kesehatan.

Pelatihan ini dimaksudkan untuk memberikan keterampilan pada kalangan remaja maupun pemuda dalam membuat media promosi kesehatan. Sehingga media yang mereka buat dapat diakses oleh teman-teman sebaya mereka. Minimnya informasi kesehatan untuk kalangan remaja menjadikan pelatihan ini sangat bermanfaat khususnya untuk menambah informasi kesehatan bagi kalangan remaja serta meningkatkan keterlibatan remaja dalam edukasi kesehatan remaja bidang kesehatan. Di era keterbukaan informasi ini maka perlu dibuat media yang kreatif yang dapat menarik minat para remaja. Sehingga informasi terkait kesehatan dapat tersampaikan dengan baik. Penting bagi kalangan remaja untuk tahu tentang informasi kesehatan sehingga dapat menjaga dirinya serta masa depannya.

\section{B. METODE PELAKSANAAN}

Pelaksana pengabdian menggunakan metode skill development. Ringkasan metode pelaksanaan beserta jam kerja tersaji pada Tabel I.

Tabel I. Metode, Kegiatan, Jam Kegiatan dan keterlibatan mahasiswa

\begin{tabular}{|l|l|l|l|c|}
\hline No & Metode & Kegiatan & Jam Kegiatan & $\begin{array}{l}\text { Jumlah Mahasiswa } \\
\text { yang terlibat }\end{array}$ \\
\hline 1 & Ceramah & $\begin{array}{l}\text { Penjelasan Materi Pengenalan } \\
\text { Media Promosi Kesehatan } \\
\text { Tahapan dan Teknik dalam } \\
\text { merancang Media Promosi } \\
\text { Menyusun Pesan Kesehatan yang } \\
\text { Persuasif } \\
\begin{array}{l}\text { Penggunaan Media Sosial dalam } \\
\text { promosi Kesehatan }\end{array}\end{array}$ & $2 \times 45$ Menit & 2 \\
\hline
\end{tabular}


Diterbitkan oleh Lembaga Pengabdian kepada Masyarakat

Universitas Ahmad Dahlan Yogyakarta

\begin{tabular}{|l|l|l|l|c|}
\hline 2 & Praktek & Praktek Media Grafis (Leaflet) & $2 \times 60$ Menit & 2 \\
& & Praktek Media Grafis (Poster) & $2 \times 60$ Menit & 2 \\
& Praktik Audiovisual & $2 \times 60$ Menit & 2 \\
& Praktek Pembuatan Blog & $2 \times 60$ Menit & 2 \\
\hline
\end{tabular}

\section{HASIL, PEMBAHASAN DAN DAMPAK}

1. Profil Peserta

Peserta dalam pelatihan perancangan media promosi kesehatan adalah angkatan muda Muhammadiyah.

2. Gambaran Pelaksanaan

a. Pemaparan materi pelatihan perancangan media promosi kesehatan pada kalangan remaja pada gambar 1.

b. Keterlibatan mahasiswa dalam pelatihan perancangan media promosi kesehatan pada kalangan remaja pada gambar 2 .

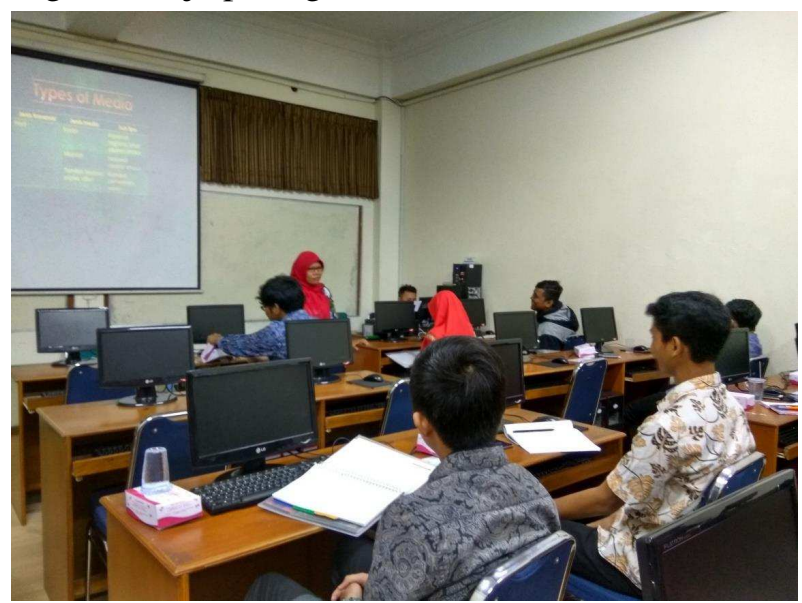

Gambar 1. Pemaparan Materi

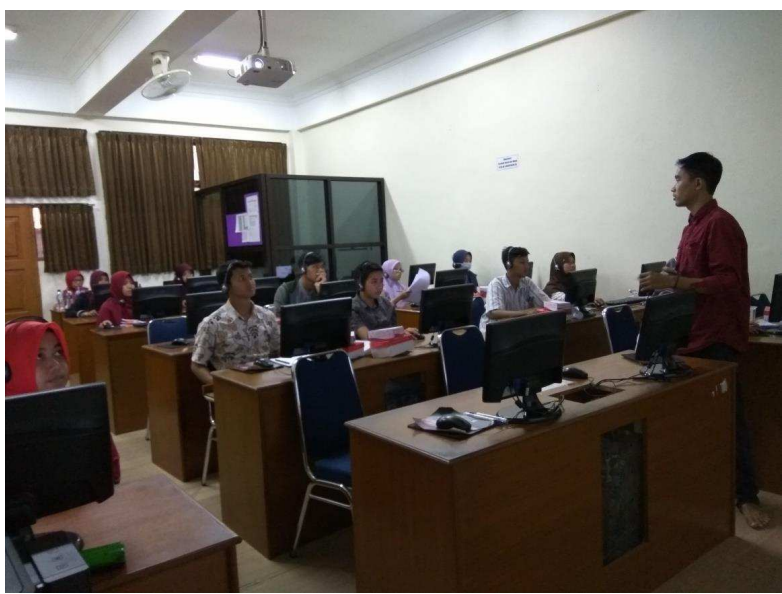

Gambar 2. Keterlibatan Mahasiswa dalam Pelatihan 
Berdasarkan gambar 1 dan 2 menunjukkan bahwa kegiatan pelatihan perancangan media promosi kesehatan pada angkatan muda Muhammadiyah dapat terlaksana dengan adanya partisipasi dan antusias yang tinggi dari angkatan muda Muhammadiyah. Pelaksanaan kegiatan pelatihan ini juga melibatkan mahasiswa. Keterlibatan mahasiswa dalam hal ini sebagai fasilitator praktik pembuatan media promosi kesehatan. Pelatihan ini diharapkan memberikan manfaat langsung kepada peserta pelatihan yaitu dapat meningkatkan pengetahuan tentang media promosi kesehatan, meningkatkan keterampilan dalam merancang media promosi kesehatan serta meningkatkan keterlibatan remaja dalam edukasi kesehatan remaja bidang kesehatan.

Promosi kesehatan adalah upaya dalam meningkatkan kontrol/ kendali individu dalam rangka meningkatkan derajat kesehatannya. Setiap individu diharapkan mampu mengendalikan dirinya sendiri agar mampu menjaga dan meningkatkan status kesehatannya (RI \& Departemen Pendidikan Kesehatan dan Ilmu Perilaku, 2009). Agar setiap individu memiliki kontrol yang baik terhadap kesehatannya, maka ia memerlukan pengetahuan dan pembentukan sikap yang positif terhadap perilaku sehat (Glanz et al. 2008). Kesemuanya itu tentunya tidak bisa didapatkan dalam waktu yang singkat.

Pengetahuan adalah hasil dari tahu, yang terjadi setelah orang melakukan penginderaan terhadap objek tertentu. Sebagian besar pengetahuan diperoleh melalui mata dan telinga (Maulana, 2009). Fungsi utama dari informasi adalah menyampaikan pesan atau menyebarluaskan informasi yang bersifat mendidik kepada orang lain. Artinya, dari penyebarluasan informasi itu diharapkan para penerima informasi akan menambah pengetahuan tentang sesuatu (Liliweri 2008).

Green \& Kreuter (2000) mengemukakan bahwa pengetahuan adalah salah satu faktor yang memudahkan munculnya sebuah perilaku atau disebut predisposing factor. Pengetahuan kesehatan mungkin diperlukan sebelum tindakan kesehatan seseorang dipraktekkan, tapi tindakan kesehatan yang diinginkan tidak akan terjadi kecuali seseorang menerima isyarat yang cukup kuat untuk memicu motivasi untuk bertindak dari pengatahuan yang ia miliki. Oleh karena itu diperlukan penerapan strategi edukasi kesehatan, salah satunya dengan komunikasi tidak langsung menggunakan media pembelajaran.

Pemilihan dan penggunaan media merupakan salah satu komponen yang penting. Penyampaian informasi khususnya tentang kesehatan dapat dilakukan melalui media seperti leaflet, poster, audio visual dan blog. Pada pelatihan ini juga menerapkan metode praktek pembuatan media promosi kesehatan dalam menyampaikan informasi. Menurut Maulana (2009), pancaindera yang banyak menyalurkan pengetahuan keotak adalah mata (kurang lebih 75\% sampai 87\%), sedangkan 13\% sampai 25\%, pengetahuan manusia diperoleh dan disalurkan melalui pancaindera yang lain. Cues to action, yaitu isyarat yang didapat seseorang untuk melakukan tindakan kesehatan tertentu. Isyarat tersebut bisa didapatkan dari internal, yaitu kondisi dan gejala yang dialami individu tersebut. Sumber lain adalah isyarat dari eksternal, seperti informasi dari media atau orang lain tentang kesehatan. Informasi kesehatan bisa didapatkan dengan mudah oleh setiap orang di era digital media. 
Penelitian Kapti dkk (2013) menyebutkan bahwa penggunaan media dalam melakukan promosi kesehatan dapat meningkatkan pengetahuan. Media audiovisual merupakan media penyuluhan yang menarik dan merangsang lebih banyak indera. penggunaan media sebagai promosi kesehatan juga tidak terlepas dari target sasaran yang akan dituju. Seperti hasil penelitian yang dilakukan oleh Ambarwati, dkk (2014) yang menyebutkan bahwa penggunaan media leaflet lebih efektif diterapkan pada siswa SD sebagai media pendidikan kesehatan diband-ingkan dengan media video. Hal ini disebabkan karena pada media leaflet pesan yang disampaiakn tersurat dengan jelas, dan dapat dibaca berulang-ulang oleh siswa. Sementara pada media video terdapat kecenderungan siswa hanya menikmati alur cerita pada video tetapi kurang bisa menangkap pesan-pesan yang tersirat dalam cerita di video

\section{KESIMPULAN}

Terdapat peningkatan pengetahuan peserta tentang media promosi kesehatan dan peningkatan keterampilan peserta dalam merancang media promosi kesehatan. Hal ini terlihat dari evaluasi proses ketika praktek merancang media dan hasil perlombaan.

\section{DAFTAR PUSTAKA}

Ambarwati, Khoirotul, A.U, Kurniawati, F. Diah T. K., Darojah, S. 2014. Media Leaflet, Video Dan Pengetahuan Siswa SD Tentang Bahaya Merokok (Studi pada Siswa SDN 78 Sabrang Lor Mojosongo Surakarta). Jurnal Kesehatan Masyarakat. Vol/No 10/1, Hal 7-13

Glanz, K., Rimer, B.K. \& Viswanath, K., 2008. Health Behaviour and Health Education: Theory, Research, and Practice 4th editio, USA: Jossey Bass. Available

Parvanta, C. et al., 2011. Essentials of Public Health Communication R. Riegelman, ed., USA: Jones \& Bartlett Learning.

RI, P.P.K.D.K. \& Departemen Pendidikan Kesehatan dan Ilmu Perilaku, F.U., 2009. Promosi Kesehatan Komitmen Global Dari Ottawa- Jakarta - Nairobi Menuju Rakyat Sehat, Jakarta: Departemen Kesehatan Republik Indonesia.

Green, LW. \& Kreuter, MW. 2000. Health Promotion Planning: An Educational and Environmental Approach. Second Edition. USA: Mayfield Publishing Company.

Kapti, R.E., Rustina, Y., Widyastuti. 2013. Efektifitas Audiovisual Sebagai Media Penyuluhan Kesehatan Terhadap Peningkatan Pengetahuan Dan Sikap Ibu Dalam Tatalaksana Balita Dengan Diare Di Dua Rumah Sakit Kota Malang. Jurnal Ilmu Keperawatan. Vol/No 1/1, Hal 53-60

Kemm, J. \& Close, A. 1995. Health Education: Theory \& Practice. London: Macmillan Press.

Liliweri, Alo. 2008. Dasar-Dasar Komunikasi Kesehatan. Yogyakarta: Pustaka pelajar Maulana, Heri. 2009. Promosi Kesehatan. Jakarta: Penerbit Buku Kedokteran EGC. Sarwono, SW. 2012. Psikologi Remaja. Jakarta: PT. Grafindo Persada.

Simons-Morton, BG., Greene, WH., \& Gottlieb, NH. 1995. Introduction to Health Education and Promtion. Second Edition. USA: Waveland Press. 
